\title{
Congenital Midline Nasal Masses: Diagnosis and Management
}

CHARLES D. KENNARD, M.D. JAMES E. RASMUSSEN, M.D.

\begin{abstract}
Congenital midline nasal masses (CMNMs) are rare lesions most commonly caused by dermoids, hemangiomas, nasal gliomas or encephaloceles. We report a case of nasal glioma and discuss the embryologic development, evaluation, and management of such CMNMs. J Dermatol Surg Oncol 1990; 16:1025-1036.
\end{abstract}

Congenital midline nasal masses (CMNMs) occur in only 1 of every 20,000 to 40,000 live births. ${ }^{1}$ They are usually obvious at birth, but some CMNMs may not be recognized until well into adulthood. ${ }^{2}$ The most common lesions producing CMNMs are, in order of decreasing frequency: dermoids, hemangioma, nasal glioma, and encephalocele. ${ }^{3}$ Nasal gliomas are rare, benign tumors of heterotopic brain tissue thought to arise from the abnormal extracranial sequestration of neural elements during embryologic development. Since nasal gliomas and other CMNMs may have intracranial extensions, familiarity with the differential diagnosis and appropriate evaluation

Charles D. Kennard, M.D., Fellow, Dermatologic Surgery and Cutaneous Oncology, is from the Department of Dermatology, University of Iowa Hospitals and Clinics, Iowa City, Iowa.

James E. Rasmussen, M.D., is from the Department of Dermatology, University of Michigan, Ann Arbor, Michigan.

Reprints are not available.

(C) 1990 by Elsevier Science Publishing Co., Inc. $\bullet 0148-0812 / 90 / \$ 3.50$ of such lesions are critical to their safe and effective management.

\section{CASE REPORT}

A 1-week-old male infant was referred to the Department of Dermatology for evaluation of a congenital mass at the root of the nose that had not changed since birth. There was no history of nasal blockage, discharge, bleeding, seizures, or meningitis. The patient's mother believed that the lesion transiently increased in size when the child was crying. He was a full-term child, the product of a normal labor and delivery and no other abnormalities were identified. There was no history of congenital defects in three older siblings and the family history was unremarkable.

Physical examination revealed a $1-\mathrm{cm}$, firm, moveable, nonpulsatile mass located at the root of the nose just slightly left of midline (Fig. 1). There was a slight prominence to the vascularity of the overlying skin, but no other changes in the skin surface were seen. There were no intranasal masses and hypertelorism was not present. The remainder of the physical examination was unremarkable.

The clinical differential diagnosis was nasal glioma, encephalocele, and cavernous hemangioma. The patient was referred to the Pediatric Neurosurgery service, which favored the diagnosis of encephalocele. An MRI scan (Figs. 2 and 3) showed a soft tissue mass in the left nasal region. There was no evidence of fluid or blood in the mass. There was no alteration of the parenchyma of the brain and no transcranial extension of the mass (Fig. 4).

The patient was referred to the Plastic Surgery service, where the mass was excised under general anes- 


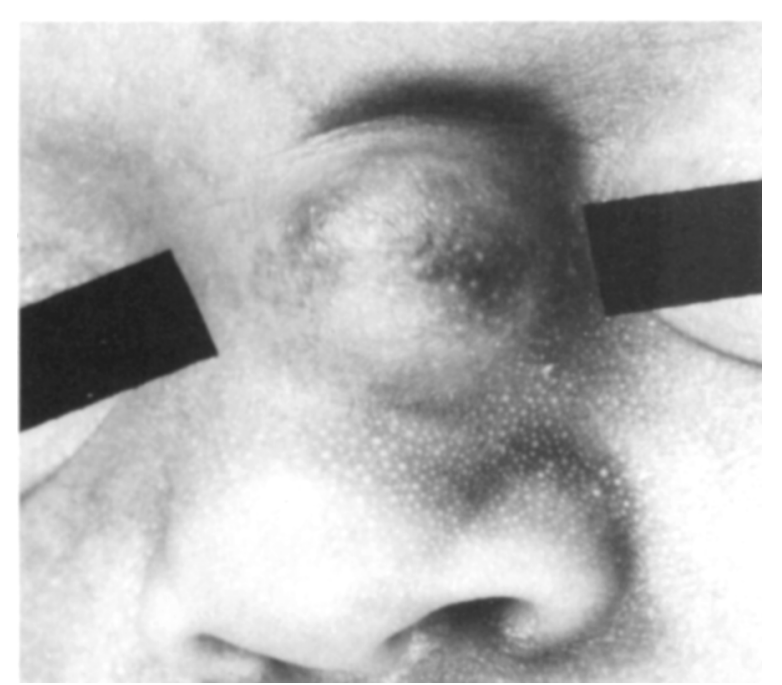

FIGURE 1. Nasal glioma.

thesia. An eliptical excision exposed a cystic lesion within the dermis that, upon dissection, was found to have eroded the distal nasal bone on the left and to have partially eroded the nasal septum and nasal cartilage with involvement of the nasal mucosa. The lesion was removed intact and no extensions were detected. Postoperative course was unremarkable, and the patient was well at 1 month postoperatively.

Histologic exam showed that the epidermis was near normal for the area. The density of adnexal structures was decreased and the dermis extensively altered by the inclusion of glial tissue arranged in irregular and somewhat angular islands (Fig. 5). The combination of glial tissue and collagen extended to the deep fascia. Large, syncytial, multinucleated giant cells were formed by syncytial aggregates of glial cells (Fig. 6). These changes were interpreted as diagnostic of nasal glioma. Ganglion cells were not identified.

\section{DISCUSSION}

Up to $50 \%$ of congenital malformations involve the cerebrospinal axis. ${ }^{3}$ The majority of these are found caudally, but the cranium may also be affected; CMNMs are rarer still.

Patients with CMNMs are usually managed by neurosurgeons, otorhinolaryngologists, and plastic surgeons. However, dermatologists may be consulted for the evaluation of unusual subcutaneous masses
FIGURE 2. MRI sagittal scan demonstrates extranasal mass with involvement of nasal bones. No communication with intracranial contents is seen.

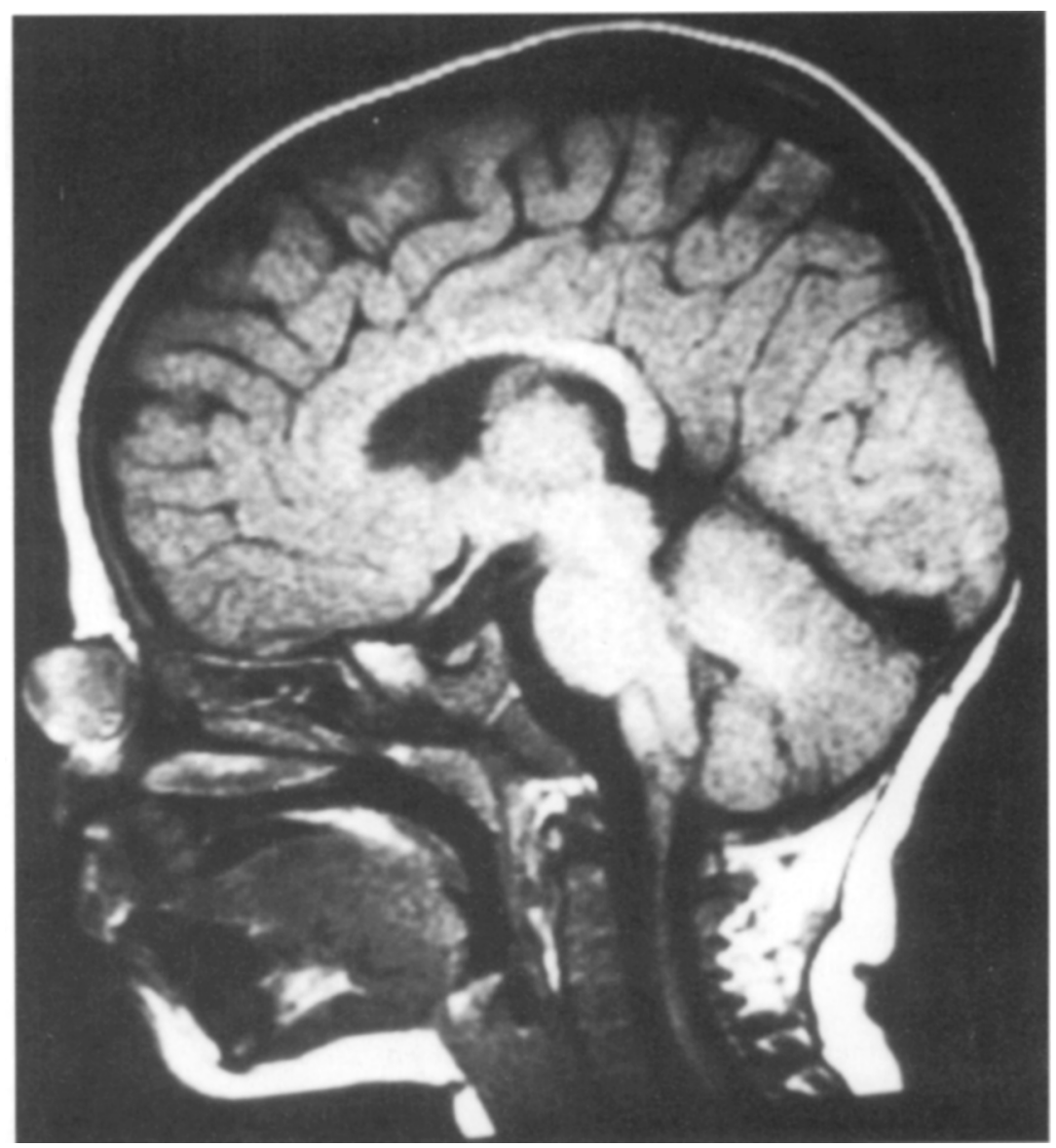

J Dermatol Surg Oncol 16:11 November 1990 


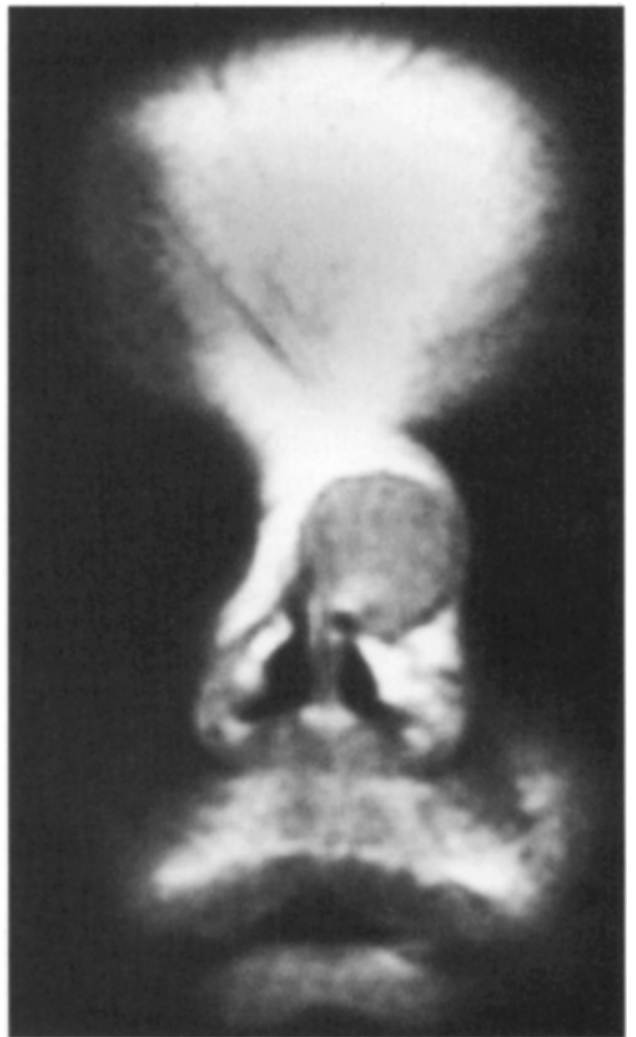

FIGURE 3. MRI coronal scan shows soft tissue mass distorting nasal cartilage and expanding soft tissue.

of the nose in an infant or young child.4-7 The differential diagnosis of such lesions has been assembled by several authors ${ }^{8-10}$ and may include developmental anomalies, inflammatory lesions, and benign or malignant neoplasms (Table 1). In a series of 109 consecutive admissions to two children's hospitals over a 20-year period for evaluation of nasal masses present from birth or with onset in early childhood, Bradley and Singh $^{8}$ found 67 nasal dermoids, 32 hemangiomas, 5 nasal gliomas, 2 encephaloceles and 3 other entities (Table 2). During the same time period, a total of 304,000 admissions had been made to the same hospitals, demonstrating the rarity of CMNMs.

\section{Embryologic Development}

Since the majority of CMNMs result from an alteration of the embryologic events that produce the nose, frontal-basal skull, and intracranial contents, ${ }^{1,11,12}$ a review of the normal sequence will be useful in understanding the results of aberrant developmental pathways. The neuroectoderm first appears in the human embryo at about 18 days after conception; folding of this neural plate and fusion to produce the neural tube follows. The anterior portion of this neural tube, the anterior neuropore, fuses at about 24 days of gestation. At the same time, meso-

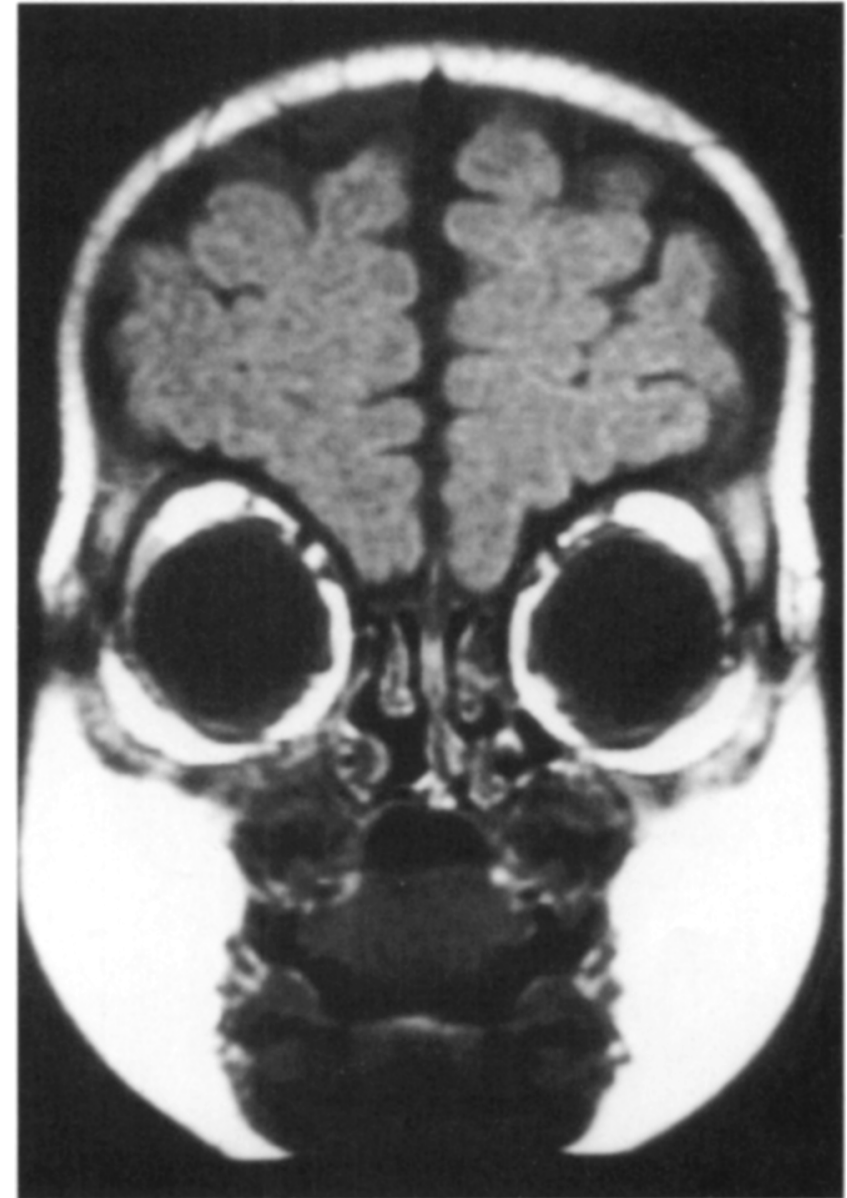

FIGURE 4. MRI coronal scan demonstrating normal cribiform plate and crista galli.

dermal tissues begin to form the bone, cartilage, vessels, and meninges of the skull. A space called the fonticulus frontalis, or nasofrontal fontanel, lies between the frontal and nasal bones. A cartilagenous capsule, which ultimately will form the upper lateral nasal cartilage, is formed in the anterior wall of the external nose. The prenasal space extends from the brain to the nasal tip lying deep to the nasal bone and skin, and superficial to the nasal cartilage capsule. These relationships are shown in Figure 7A.

As development proceeds, the nasofrontal fontanel is altered by extensions of the frontal bones to form a canal (foramen caecum) through which a projection of dura-mater extends to traverse the prenasal space and contact the nasal skin (Fig. 7B). Progressively, the frontal, nasal, sphenoid, and ethmoid bones fuse to form the base of the skull and cribiform plate. The dural tract in the prenasal space separates from the nasal skin and is obliterated (Fig. 7C).

Alterations in this cycle can include faulty closure of the anterior neuropore with defects in the fonticulus frontalis, foramen caecum, cribiform plate, or 


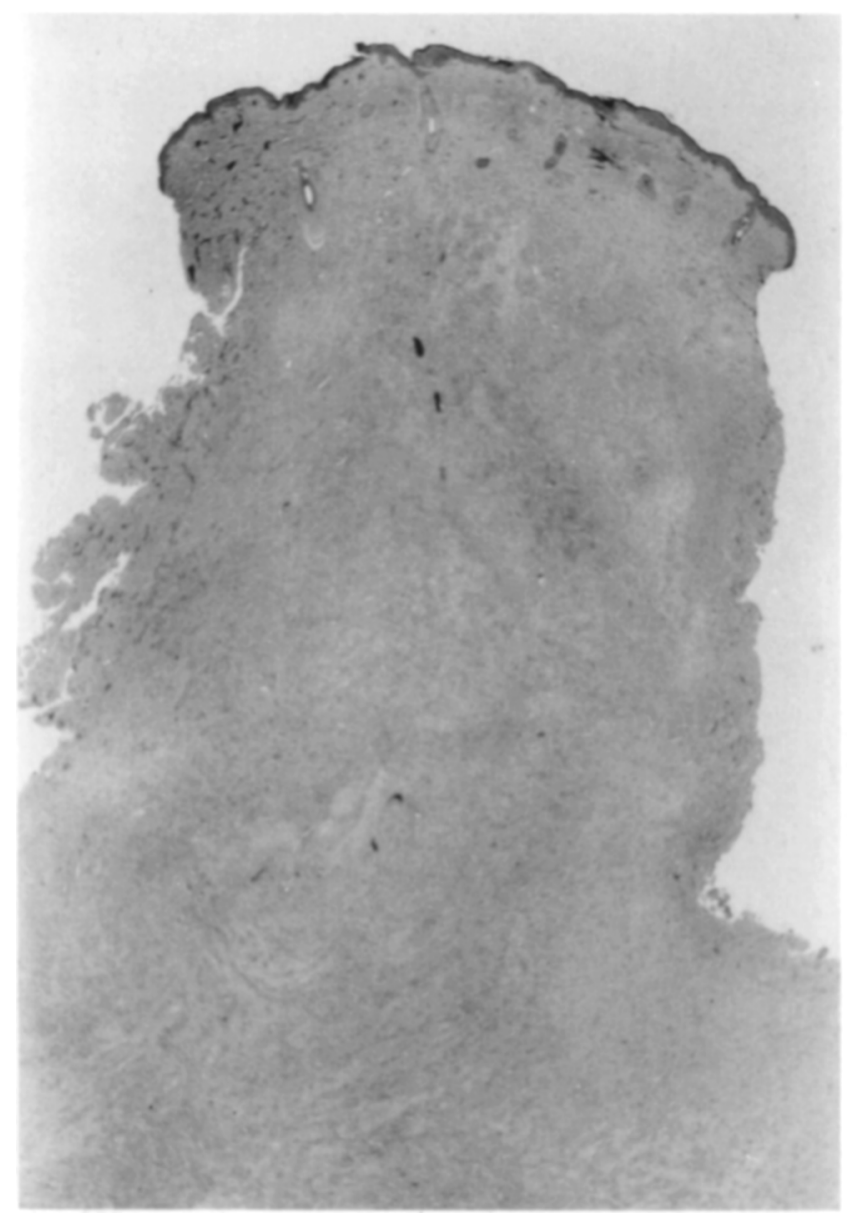

FIGURE 5. Nasal glioma excision. Lightly stained strands of glial tissue infiltrate the dermis. (Original magnification, $\times 2.5)$.

sphenoid and ethmoid bones. ${ }^{1,13}$ When bony defects such as these allow herniation of dura-mater and brain tissue extracranially, an encephalocele results (Fig. 8). Gliomas, or rests of neuroglial tissue, result when brain tissue is isolated extracranially by the fusion of cranial sutures without the inclusion of meninges, although a fibrous stalk may persist (Fig. 9). In addition to the frontonasal, or "extranasal" lesions, which can result from herniation through the fonticulus frontalis (Figs. 8 and 9), frontosphenoidal or "intranasal" lesions can be produced by herniation through the foramen caecum (Figs. 10 and 11).

The development of nasal dermoid cysts and sinuses is now understood to result from the faulty involution of the dural tract, which traverses the prenasal space early in embryologic development. ${ }^{11,13,14}$ Ectodermal elements may be found along this tract. Also, as the dural tissue retracts into the cranium through the foramen caecum it may draw somatic ectoderm along with it, producing a sinus tract or cyst anywhere along this path (Figs. 12 and 13). Dural 1028 projections may also exist in the region of the fonticulus frontalis, perhaps accounting for the occurrence of frontonasal dermoids (Fig. 14). ${ }^{11}$

Other theories to explain the formation of nasal dermoids include the following: faulty closure of the fonticulus frontalis or foramen caecum, which may permit dermal elements to invaginate into these areas; ${ }^{\mathbf{1 2 , 1 5}}$ inclusion of dermal elements in facial clefts; ${ }^{16}$ simple inclusion cysts; ${ }^{17}$ and aberrant development of skin appendages. ${ }^{18}$

Hemangiomas are thought to be a proliferation of endothelial cells resulting from an aberrant development of an embryologic undifferentiated capillary network. ${ }^{19}$ The factors that enhance the growth of hemangiomas may include locally-produced angiogenic factors, ${ }^{20}$ mast cells-derived factors, ${ }^{21}$ increased serum $17 \beta$-estradiol levels, and increased specific $17 \beta$-estradiol binding sites within hemangiomas, ${ }^{22}$ or a deficiency of a normal inhibitor.

\section{Nasal Glioma}

Nasal glioma was first reported in 1852 by Reid. ${ }^{23}$ Schmidt gave a detailed description of the entity and coined the term "glioma" in $1900 .{ }^{24}$ Since then, approximately 150 cases have been reported. ${ }^{25-27}$ Nasal gliomas occur with a male to female ratio of $3: 2 .{ }^{27}$ There is no familial predisposition or any consistently associated defects. ${ }^{28}$ Nasal gliomas grow in proportion to the growth of the child. There is no reported malignant degeneration.

Clinically, nasal gliomas are extranasal in $60 \%$ of cases, intranasal in $30 \%$, and combined intra- and extranasal in $10 \% .27,29$ Heterotopic brain tissue has also been found in the scalp, ${ }^{30}$ lip, ${ }^{31}$ oropharynx, ${ }^{32}$ nasopharynx ${ }^{33}$ tongue, ${ }^{34}$ and elsewhere about the head. In their review of 62 published cases of nasal glioma, Karma et al.27 found 11 cases that demonstrated connection with the intracranial space at surgery.

Extranasal gliomas are smooth, firm, noncompressible, skin-covered nodules most often located at the bridge or root of the nose, although they may be found at the nasal tip. ${ }^{32}$ They are often located slightly to one side of the midline and range in size from 1 to $5 \mathrm{~cm}$. The overlying skin may be discolored $^{25}$ or telangiectatic. ${ }^{35}$ There is no pulsation or transillumination. They do not expand with crying or with compression of the jugular veins (negative Furstenberg test); however, this examination is not highly reliable. ${ }^{36}$ There may be widening of the nasal bridge or hypertelorism, but this is more likely in intranasal glioma.

Intranasal gliomas may present as mass protruding from a nostril, or more frequently, as a pale, glis- 
FIGURE 6. Microscopic detail of nasal glioma. Glial tissue extends through reticular dermis, at some points forming syncytial multinucleated giant cells. (Original magnification, $\times 100$ ).

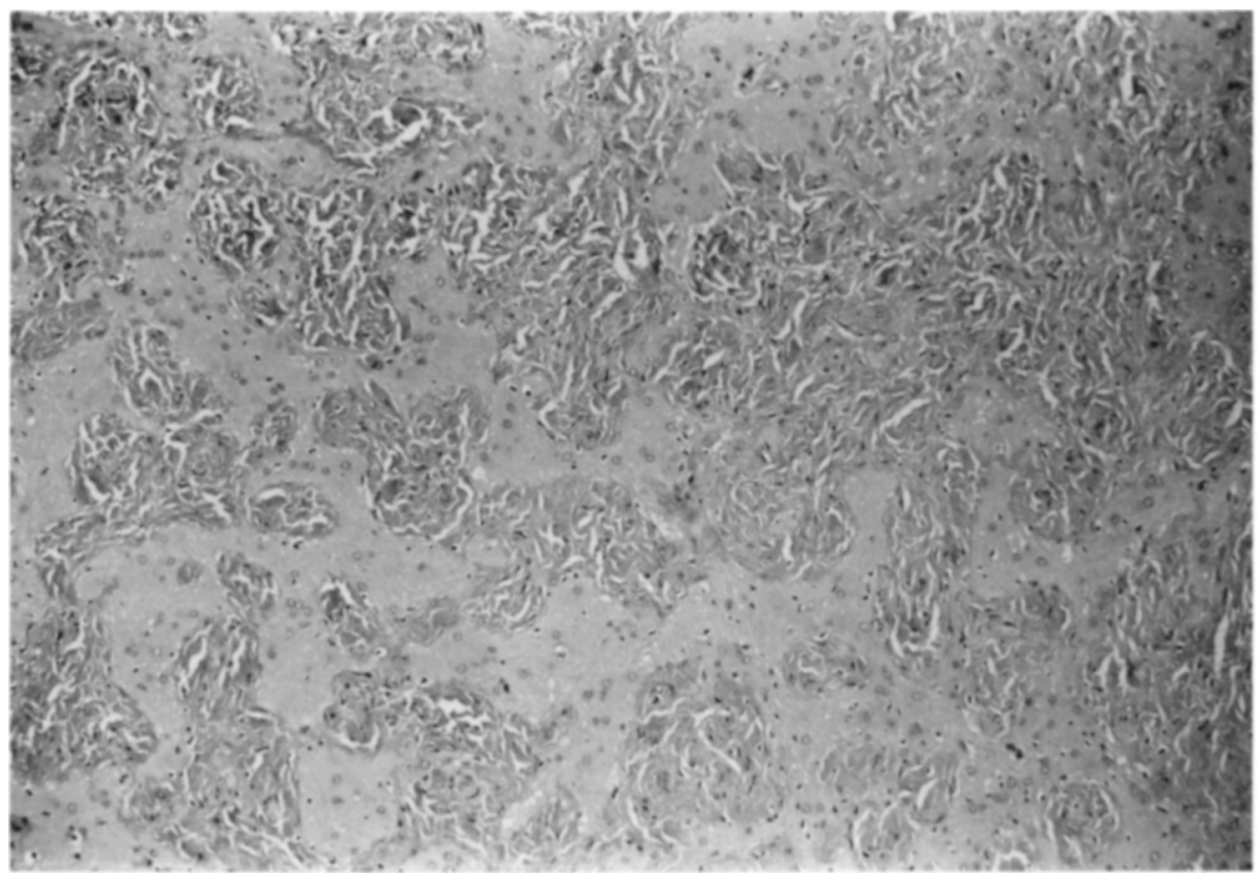

tening, polypoid mass within the nasal cavity or nasopharynx. ${ }^{30,37,38}$ Nasal obstruction with respiratory embarrassment may occur. Rarely, there is epistaxis or spontaneous cerebrospinal fluid leakage. ${ }^{39}$ The base of the intranasal glioma usually arises on the lateral nasal wall near the middle turbinate or from the middle turbinate itself; occasionally they originate from the nasal septum. ${ }^{37,38}$

TABLE 1

The Differential Diagnosis of CMNMs ${ }^{1,4,8,9,10}$

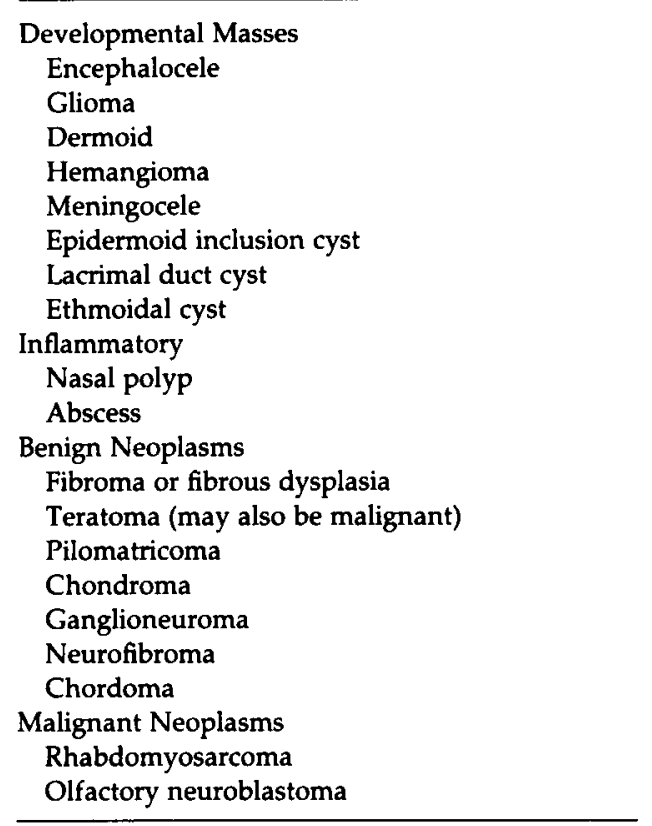

J Dermatol Surg Oncol 16:11 November 1990
Histologically, nasal gliomas consist of unencapsulated rests of glial cells, predominantly astrocytes, embedded in varying amounts of fibromuscular stroma.4,27,30,38,40,41 Multinucleated giant cells are often seen, but mitotic figures are rare or absent. Neurons have been identified in $10 \%-60 \%$ of cases in series reported. ${ }^{27,39,41}$ Reactive changes and local calcifications as seen in some nasal gliomas ${ }^{11}$ may reflect the relatively poor blood supply to these heterotopias, which may also explain the paucity of neurons. ${ }^{39}$

Ependymal-lined structures and choroid plexuslike structures may also be found, especially in pharyngeal lesions. ${ }^{41}$ Electron microscopic examinations $5,28,38,41$ have shown intracellular filaments and gap junctions typical of astrocytes. Myelinated nerve fibers have also been reported occasionally. ${ }^{39}$

TABLE 2

Final Diagnosis of 109 Cases of Midline Nasal Masses Presenting at Birth or in Early Childhood $^{8}$

\begin{tabular}{lr}
\hline \multicolumn{1}{c}{ Diagnosis } & Number \\
\hline Nasal dermoid & \\
"True dermoid" cyst & 28 \\
Epidermoid cyst & 39 \\
Hemangioma & 32 \\
Nasal glioma & 5 \\
Encephalocele & 2 \\
Calcifying epithelioma & 1 \\
Fibroma & 1 \\
Neurofibroma & 1 \\
\hline
\end{tabular}


FIGURE 7. Sequence of normal embryologic development of the frontobasal skull and nose. (A) Early developmental stage illustrating the relationships between external nasal cartilage, nasal bone and frontal bone, and the two potential spaces of the fonticulus frontalis and the prenasal space. (B) Formation of foramen caecum by partial fusion of nasal bone and frontal and basal skull, demonstrating the dural process extending to nasal skin. (C) Complete closure of foramen caecum and obliteration of nasal neuroectodermal elements. (After Sessions. ${ }^{11}$ )
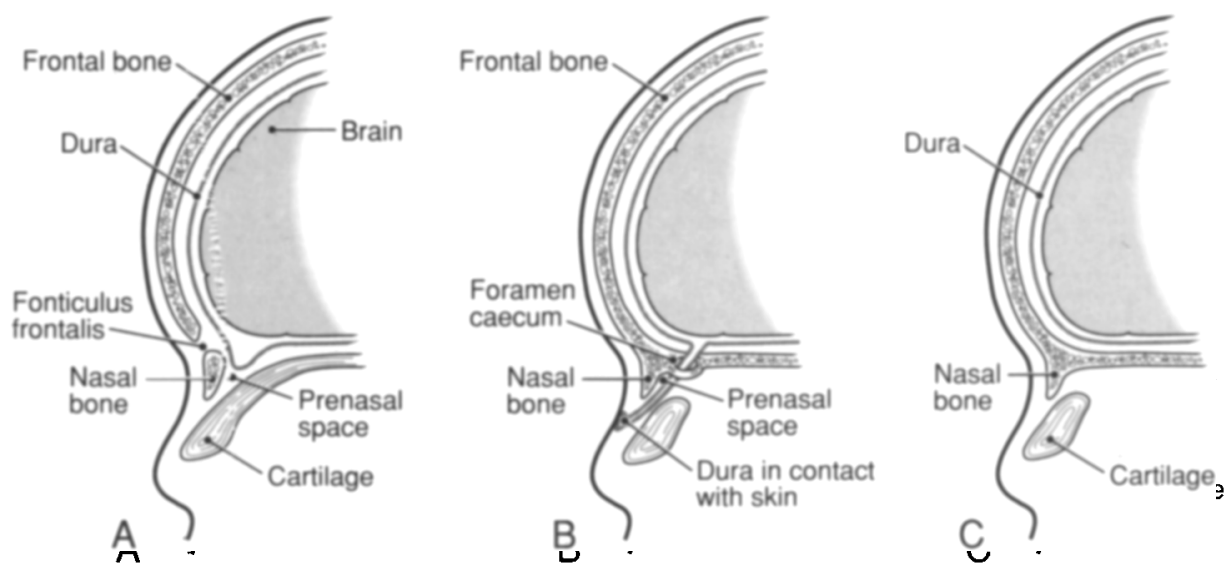

\section{Encephalocele}

An encephalocele is a herniation of cranial contents through a defect in the skull. The first medical report of encephalocele may have appeared in the 16th century. ${ }^{42}$ Encephaloceles occur in about 1-3 out of 10,000 live births, ${ }^{43,44}$ and affect the sexes equally. Of these, $75 \%$ are located at the occiput; $15 \%$ are sincipital, or extranasally situated about the dorsum of the nose, orbits, and forehead; and $10 \%$ are basal, or found in the intranasal, sphenomaxillary, or pharyngeal regions. There is a $6 \%$ risk of CNS abnormality in subsequent siblings. ${ }^{44}$ No malignant degeneration is found.

The classification of encephaloceles may also be made on the contents of the extracranial herniation. Meningoceles contain only meninges; meningoencephaloceles, or simply encephaloceles, contain neural tissue as well as meninges; and meningoencephalocystoceles contain meninges and neural tissue as well as a portion of the ventricular system. ${ }^{1,45}$ The following discussion will utilize the term encephalocele to encompass these entities as they relate to CMNMs.

The etiology of encephaloceles is uncertain. Apparently, most lesions are sporadic developmental defects. However, the occurrence of encephaloceles in families with other CNS malformations, in association with known genetic syndromes such as frontonasal dysplasia, and in the HARD + E syndrome (hydrocephalus, agyria, retinal dysplasia, and encephalocele) suggests that genetic influences may occur in some cases. ${ }^{46,47}$ Additionally, teratogens such as trypan blue and excess doses of vitamin A can cause encephaloceles in experimental animals. ${ }^{48}$

Clinically, both basal and sincipital encepahloceles are softer or more compressible than nasal gliomas, and they often have a bluish tint. ${ }^{1}$ They may range in size from less than $1 \mathrm{~cm}$ in diameter to a large mass containing nearly half the brain. ${ }^{46}$ They may spontaneously leak CSF, and a history of meningitis may be obtainable. The Furstenberg test is usually positive and spontaneous pulsation may be seen. ${ }^{1}$ Transillumination may be decreased if neural elements are present in the herniated sac.

Hypertelorism is frequent (Fig. 15) and associated facial and cerebral malformations such as facial clefting (Fig. 16), depressed nasal tip, and agenesis of the corpus callosum may be noted. ${ }^{48,49}$ There is always an underlying defect of the cranium.1,46 Intranasal encephaloceles may produce obstruction, and such lesions may be confused with a nasal polyp - a lesion which is usually not found in infants or young children. ${ }^{8}$

Histologically, the differentiating feature between an encephalocele and a nasal glioma is the presence of dura and leptomeninges. ${ }^{40}$ Mature neural tissue with varying degrees of organization may be found in both entities, and unfortunately, leptomeninges are not always recognizable. In such cases, the distinction between nasal glioma and encephalocele can be made only with clinicopathologic correlation. ${ }^{40}$

\section{Nasal Dermoid}

In 1982, Sessions 11 proposed the term "nasal dermal sinus-cyst" (NDSC) for a group of rare lesions of somatic ectodermal or mixed somatic and neuroectodermal derivation arising on the nose with occasional growth to and rarely through the cranium. Such NDSCs, or nasal dermoids as they are more frequently called, account for approximately $10 \%$ of all dermal sinuses of the head and neck, and for $1 \%$ of all such cysts throughout the body. ${ }^{50,51}$ The sex ratio 


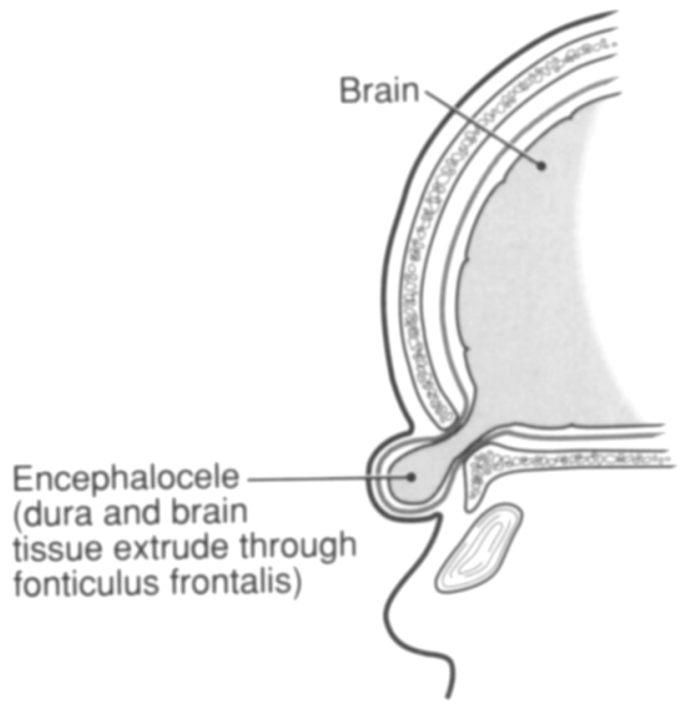

FIGURE 8. Extranasal encephalocele.

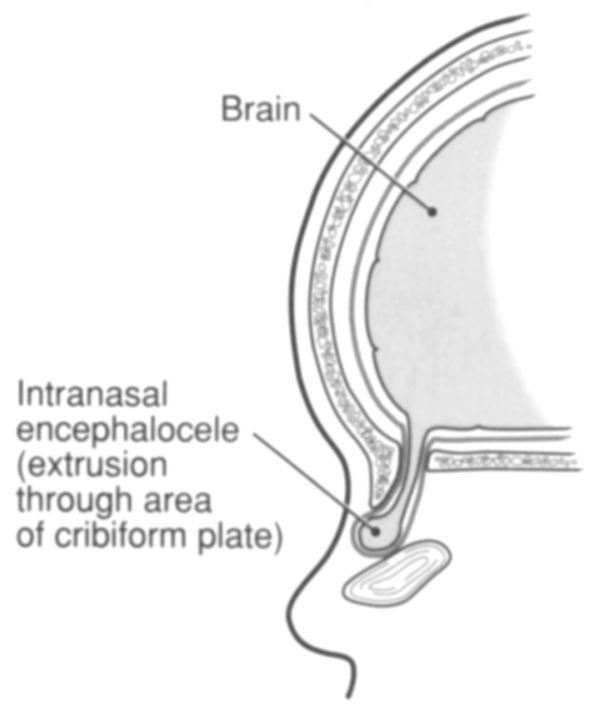

FIGURE 10. Intranasal encephalocele.

is probably equal. ${ }^{11}$ In some cases, there may be a familial predisposition to NDSC; ${ }^{-2}$ some pedigrees suggest an autosomal dominant mode of inheritance. ${ }^{53}$ Malignant degeneration has not been described, and the incidence of other concurrent congenital anomalies is quite low. ${ }^{11}$

Clinically, NDSCs have a sinus tract that opens on the skin of the nose anywhere between the base of the columella and the glabella (Figs. 17 and 18), with the distal one-third of the nasal dorsum being the most common site. ${ }^{15}$ A cheesy material can often be expressed from the sinus, and hairs are sometimes seen protruding from the opening. ${ }^{1,15}$ The course of

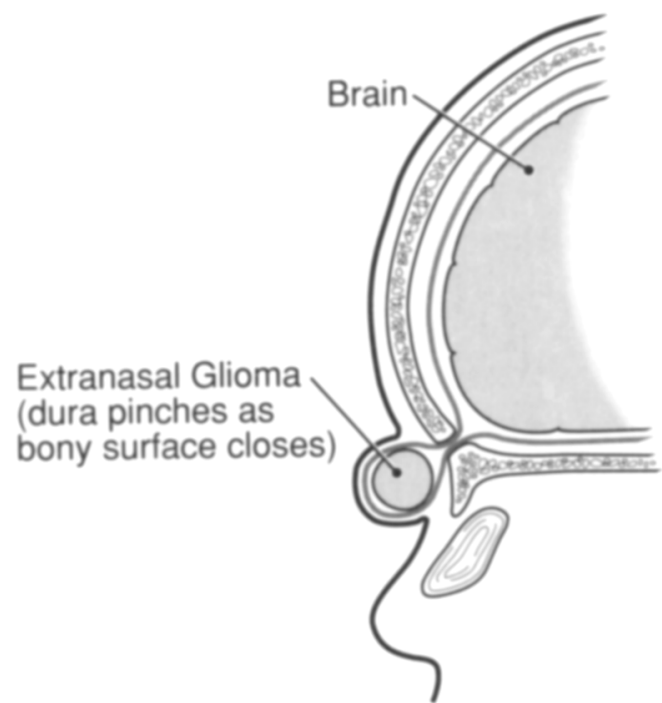

FIGURE 9. Extranasal glioma.

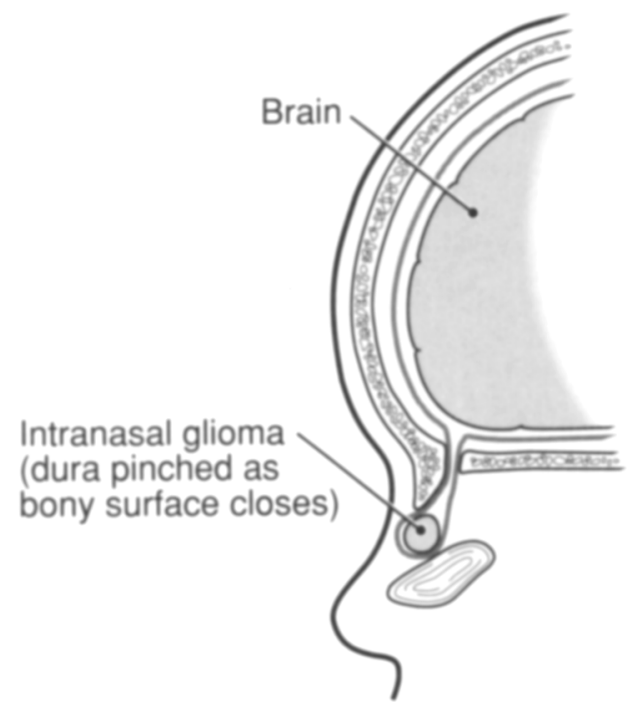

FIGURE 11. Intranasal glioma.

the sinus tract most often is deep to the nasal bones superiorly. It may be short, or extend intracranially and cystic dilatations may be found anywhere along its course (Fig. 19). ${ }^{15}$

Extranasal dermoids are firm, noncompressible, and nonpulsitile, with a negative Furstenberg test. The lesion does not transilluminate. Local infection may have occurred. If an intracranial connection exists, CSF leak may exist and meningitis, either sterile from cyst contents or bacterial through direct spread, is a risk. ${ }^{1}$

Histologically, dermoid cysts are true cysts located in the subcutaneous tissues, of ten adherent to perios- 


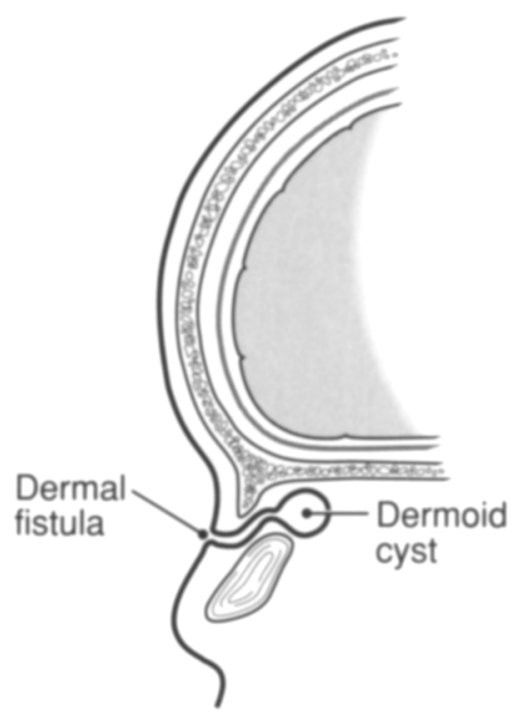

FIGURE 12. Nasal dermal sinus-cyst (dermoid) extending through prenasal space to base of skull.

teum or eroding the outer table of the skull. ${ }^{54}$ They have a lining of stratified squamous epithelium containing hair follicles. ${ }^{54}$ The lumen is filled with desquamated epithelium and hair shaft fragments. Sebaceous glands and eccrine structures are often found in the cyst wall or opening into the cyst lumen. Mesodermal elements, such as smooth muscle fibers, may also be found in the cyst. ${ }^{54}$ Bone, cartilage, and specialized tissue not usually found in the skin, such as gastrointestinal, thyroid, or respiratory tissues (as might be seen in teratomas), are absent. ${ }^{41}$

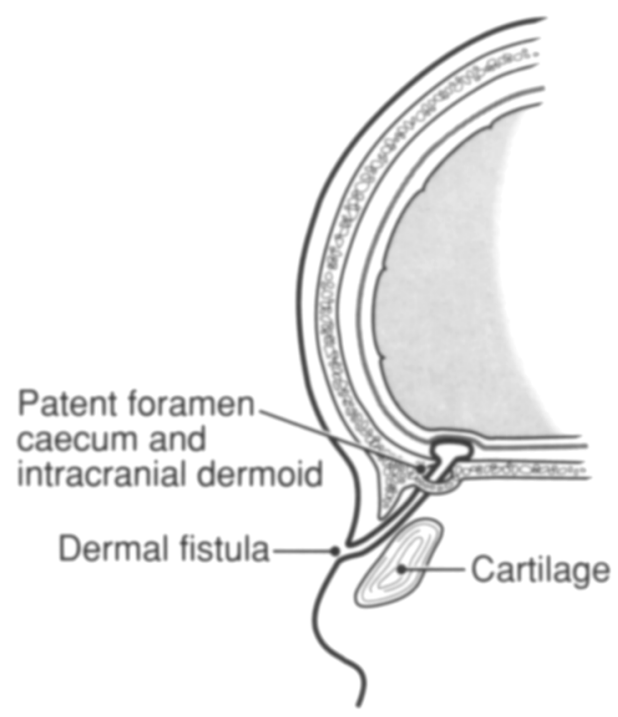

FIGURE 13. Nasal dermal sinus extending through cribiform plate with intracranial dermoid cyst.

1032

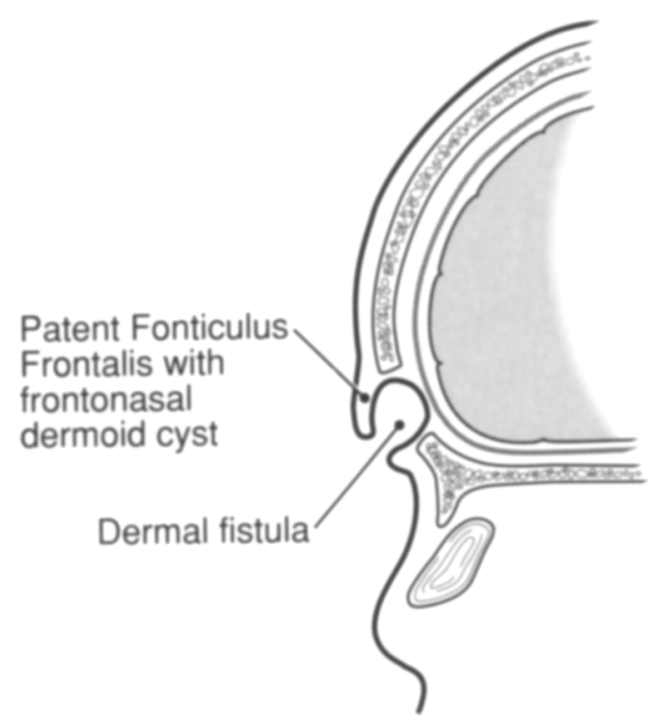

FIGURE 14. Frontonasal dermoid cyst.

\section{Other Lesions}

Hemangiomas of the nose may be quite similar in appearance to nasal gliomas (Fig. 20). Approximately $10 \%-30 \%$ of nasal hemangiomas are present at birth, and most are noted in the first few weeks of life. ${ }^{8,55}$ They may be quite firm to the touch and only partially blanchable. ${ }^{55}$ The distinction from nasal glioma may be made even more difficult because both lesions may have telangiectasia on their surface. In fact, Bradley and Singh ${ }^{8}$ reported that in their series of 109 cases of CMNMs, the greatest diagnostic uncertainty involved seven hemangiomas that were either present at birth at the glabellar/nasal root area, or where the hemangioma was deep in the nasal tip.

Typically, hemangiomas grow rapidly during the

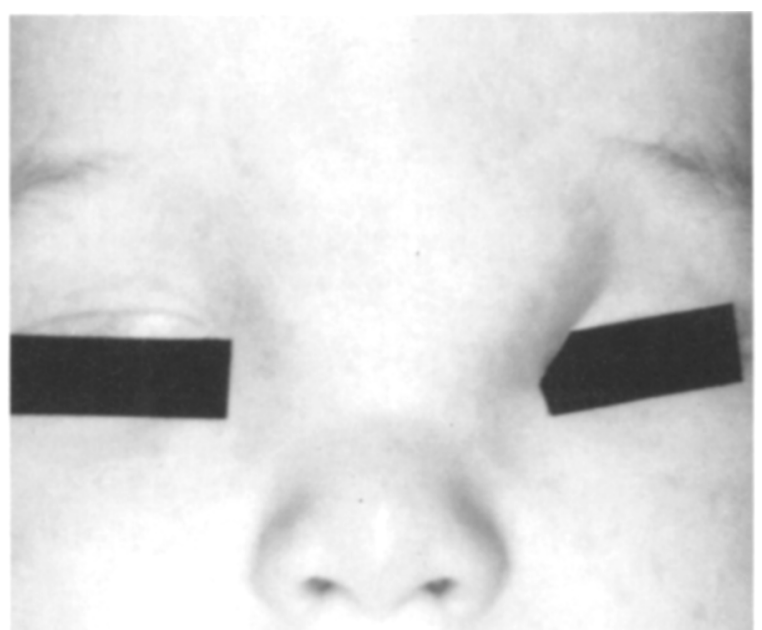

FIGURE 15. Basal encephalocele. Note mass to left of nasal root and hypertelorism.

J Dermatol Surg Oncol 16:11 November 1990 


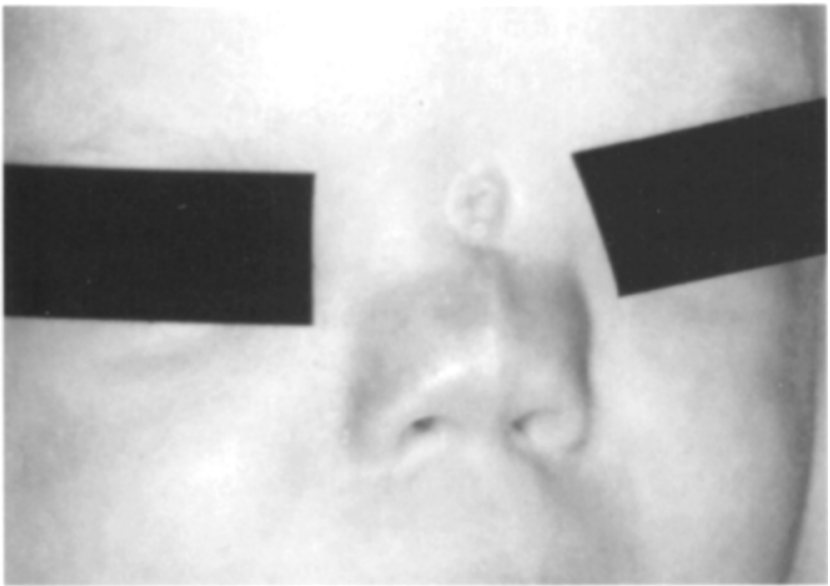

FIGURE 16. Frontonasal encephalocele. Note midline facial cleft and hypertelorism.

first weeks and months of life. This is followed by gradual involution that usually takes several years to complete. It is not unusual to see areas of breakdown in the skin overlying hemangiomas, and infection is a cause of end-stage scarring. ${ }^{55}$ Other complications include the consumptive coagulopathy of the Kassabach-Merrit syndrome, obstruction of the visual axis, and high-output congestive heart failure in association with extensive visceral and cutaneous hemangiomas. Cutaneous hemangiomas, primarily of the cervicofacial area, are seen in $50 \%$ of cases of subglottic hemangioma. ${ }^{56}$ Because hemorrhage or enlargement of a subglottic hemangioma may obstruct the airway, patients with nasal hemangiomas should be examined to rule out this potential complication.

Nasal polyps are inflammatory intranasal masses

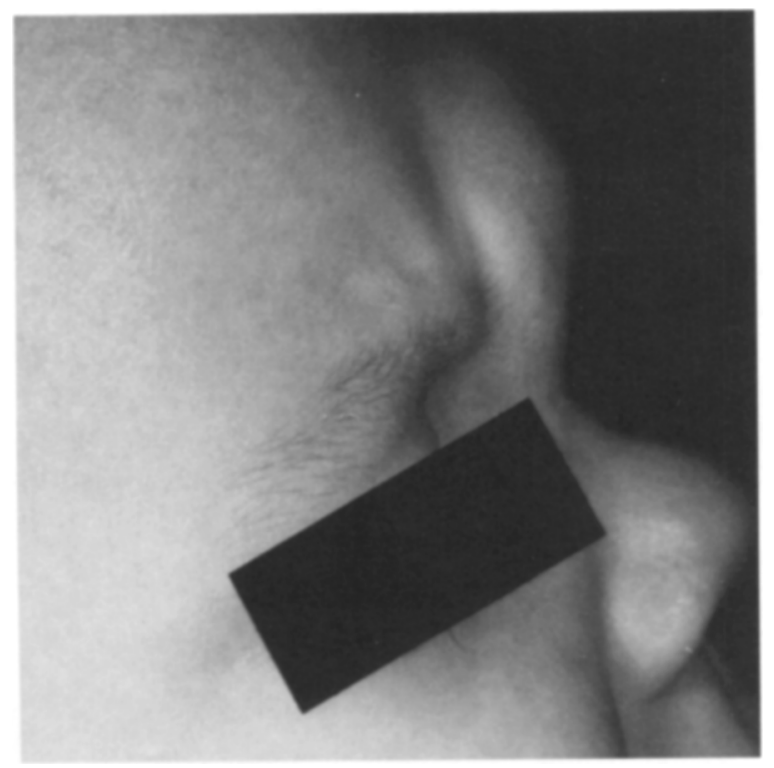

FIGURE 17. Frontonasal dermoid cyst.

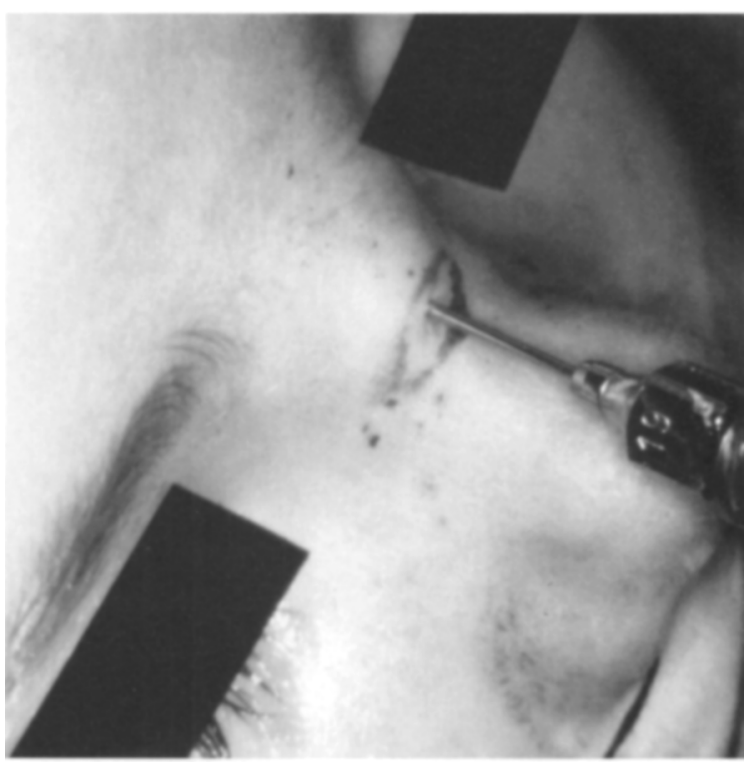

FIGURE 18. Nasal dermal sinus-cyst. Probe demonstrates ostium of sinus on dorsal nose.

associated with chronic sinusitis, or an allergic diathesis. They arise from the lateral nasal wall. They have not been reported in children younger than 3 years of age, and the cases seen in children younger than 5 years of age are often associated with cystic fibrosis. ${ }^{1,8}$

\section{Imaging Studies}

To avoid CSF leaks and meningitis, the preoperative evaluation must include imaging studies to deliniate any intracranial extension of CMNMs. Findings typi-

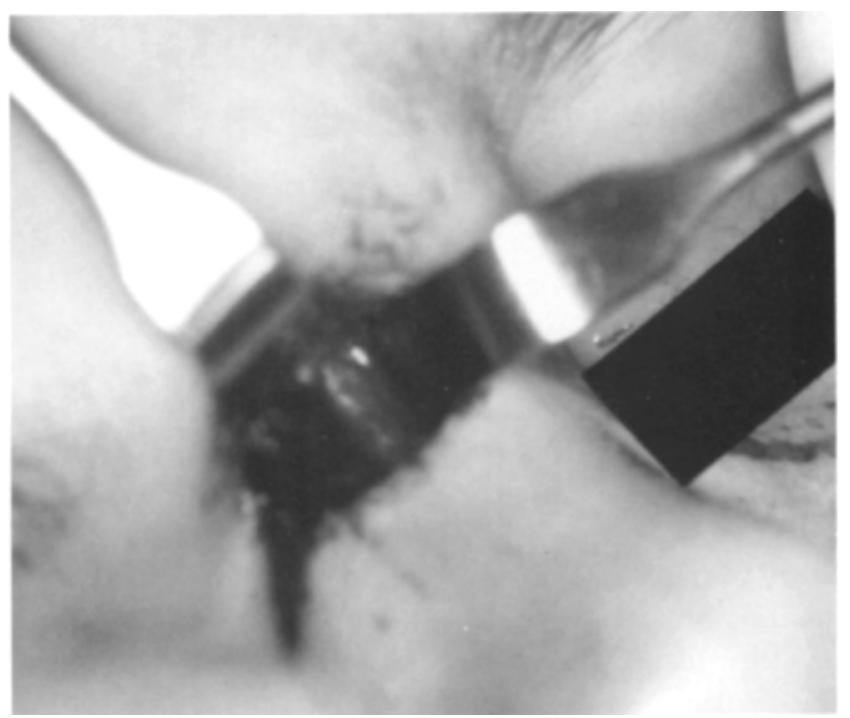

FIGURE 19. Nasal dermal sinus-cyst. Dissection of patient in Figure 17 shows sinus tract that had intracranial communication. 


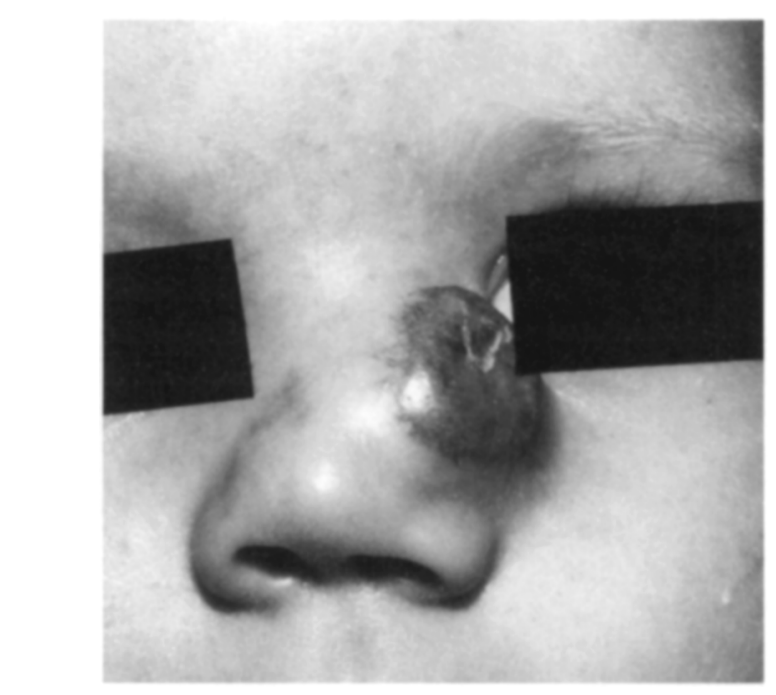

FIGURE 20. Hemangioma.

cal of all CMNMs include widening of the nasal septum, erosion of contiguous bones with the possible formation of cyst-like spaces, and increased interorbital distance. ${ }^{57}$ Polytomography and computerized tomography (CT) of the base of the skull and with coronal plane scanning are the most accurate methods of defining bony defects of the skull.1,58 However, such defects are not always linked with clinically important transcranial extensions of tissue. ${ }^{11,13}$ Magnetic resonance imaging (MRI) is superior to CT scanning in the identification of soft tissue changes in CMNMs, ${ }^{58,59}$ and has the additional advantages of sagittal and true coronal scanning.

\section{Management Strategies}

The appropriate management of patients with CMNMs requires a multidisciplinary approach from the outset. Consultations with otolaryngology or facial plastic surgery and neurosurgery services should be obtained. ${ }^{14,29}$ A detailed history should elicit whether the lesion was present at birth, whether it has increased in size, and whether it appears to enlarge with straining or crying. A history of meningitis or CSF rhinorrhea strongly suggests an intracranial extension.

Physical examination should include gentle palpation of the mass, transillumination, inspection for pulsation or sinus pit, and performance of the Furstenberg test. Needle aspiration or biopsy must be avoided until intracranial connections are ruled out, since CSF leak and meningitis may be precipitated by such maneuvers. ${ }^{15,59}$ The existence of any other congenital abnormalities should be ruled out. Imaging studies including axial, coronal, and sagittal views with MRI and axial and possibly coronal CT scans should be performed; polytomography of the base of the skull should also be considered. ${ }^{13,59}$

Hemangiomas should be managed conservatively unless their increasing size compromises respiration or the visual axis. Systemic and/or intralesional corticosteroids may be the treatment of choice for such lesions and surgical excision may be necessary in isolated cases. ${ }^{60}$

Decisions regarding the surgical resection of CMNMs should respect the known embryologic development of the lesions involved and the possibility of intracranial extension regardless of preoperative evaluations. All explorations should take place in the operating room under general anesthesia because of the possible deep extension of any of the CMNMs commonly encountered. ${ }^{8}$ Neurosurgical back-up must always be available in the event intracranial extension is identified at surgery.

If intracranial extension is identified preoperatively, the first stage procedure should be craniotomy with resection of any intracranial cysts and repair of dural defects. ${ }^{1,8}$ In such cases, the extranasal portion of the CMNS may be removed at the same time or later via an external nasal approach. ${ }^{1}$ This second stage procedure may not be necessary with encephaloceles since the risk of meningitis has been removed and the extracranially-isolated elements may regress. ${ }^{61}$

When the CMNM is suspected to be entirely extracranial, surgical therapy is indicated for enlarging or inflamed NDSCs and for nasal gliomas; asymptomatic dermal sinuses may not require surgical intervention. ${ }^{1}$ Early excision in such cases is advocated to reduce facial deformity. ${ }^{62}$ Total excision is mandatory to prevent recurrence; reported recurrence rates are about $10 \%-15 \% .{ }^{39}$ Frozen-section histologic examination of the excisional margin has been advocated. ${ }^{11}$ Mohs micrographic surgery has not been reported in the management of nasal glioma, although such tumors have apparent contiguous growth that would be amenable to such intraoperative management. A technique of detecting surgically-created CSF leaks immediately postoperatively using radionuclide tracers has been described. ${ }^{63}$

Acknowledgments. The authors wish to thank John $T$. Headington, M.D., for the histologic interpretation, Marlene Den Houter for the medical illustrations, M. Haskell Newman, M.D., for the photographs of encephaloceles and 
dermoids, and Janet Morgan for preparation of the manuscript.

\section{REFERENCES}

1. Hughes GB, Sharpino G, Hunt W, Tucker HM. Management of the congenital midline nasal mass: A review. Head Neck Surg 2:222-233, 1980.

2. Ogura JH, Shenck N. Unusual nasal tumors. Otolaryngol Clin $\mathbf{N}$ Amer 6:813-837, 1973.

3. Record RG, McKeown T. Congenital malformations of the central nervous system: I. A survey of 930 cases. Brit J Soc Med 3:183-219, 1949.

4. Fletcher CDM, Carpenter G, McKee PH. Nasal glioma: A rarity. Am J Dermatopathol 8:341-346, 1986.

5. Gebhart W, Hohlbrugger H, Lassman H, Ramadan W. Nasal glioma. Int J Dermatol 21:212-215, 1982.

6. Kopf AW, Bart RS. Tumor conference No. 15: Nasal glioma. J Dermatol Surg Oncol 4:128-130, 1978.

7. Christianson HB. Nasal glioma: Report of a case. Arch Dermatol 93:68-70, 1966.

8. Bradley PJ, Singh SD. Congenital nasal masses: Diagnosis and management. Clin Otolaryngol 7:87-97, 1982.

9. Dupin CL, LeJeune FE. Nasal masses in infants and children. South Med J 71:124-128, 1978.

10. Macomber WV, Want MKH. Congenital neoplasms of the nose. Plast Reconstr Surg 11:215-229, 1953.

11. Sessions RB. Nasal dermoid sinuses - new concepts and explanations. Laryngoscope 92:1-28, 1982.

12. Pratt LW. Midline cysts of the nasal dorsum: Embryologic origin and treatment. Laryngoscope 75:968-980, 1965.

13. McQuown SA, Smith JD, Gallo AE. Intracranial extension of nasal dermoids. Neurosurg 12:531-535, 1983.

14. Brunner $\mathrm{H}, \mathrm{Harned} J W$. Dermoid cysts of the dorsum of the nose. Arch Otolaryngol 36:86-94, 1942.

15. Mazzola PF. Congenital malformations in the fronto-nasal area - pathogenesis and classification. Clin Plast Surg 3:573-609, 1976.

16. Evans $\mathrm{JH}$, Oxon $\mathrm{MCH}$. Median congenital fissures, fistulae and dermoid cysts of the nose. Br J Child Dis 8:535-539, 1911.

17. Luongo RA. Dermoid cysts of nasal dorsum. Arch Otolaryngol 17:755-759, 1933.

18. Ellis BE. Congenital cysts of the nasal bridge. Trans Am Laryngol Rhinol Otol Soc 167-171, 1947

19. Kaplan EN. Vascular malformation of the extremities. In Williams HB (ed): Symposium on Vascular Malformations and Melanotic Lesions. St. Louis, CV Mosby, 1983, p 144.

20. Wolf JE, Hubler WR, Jr. Tumor angiogenic factor and human skin tumors. Arch Dermatol 111:321 -327, 1975.

21. Glowacki J, Mulliken JB. Mast cells in hemangiomas and vascular malformations. Pediatrics 70:48-51, 1982.

22. Sasaki GH, Pang CY, Witliff JL. Pathogenesis and treatment of infant skin strawberry hemangiomas: Clinical and in vitro studies of hormonal effects. Plast Reconstr Surg 73:359-367, 1984.

23. Reid. Uber angeborene Hirnbrucke in den stirn und Nasengegend. Illus Med Ztg 1:133, 1852.

24. Schmidt MB. Veber seltene spaltbildungen im bereiche des mittleren strinforsatzes. Virchows Arch Pathol Anat 162:340-370, 1900.

25. Black BK, Smith DE. Nasal glioma: Two cases with recurrence. Arch Neurol Psychol 64:614-630, 1950.

26. Walker EA, Resler DR. Nasal glioma. Laryngoscope 73:93-107, 1963.

J Dermatol Surg Oncol 16:11 November 1990
27. Karma P, Rasanen $O$, Karja J. Nasal gliomas: A review and report of two cases. Laryngoscope 87:1169-1179, 1977.

28. English GM. Nose, glioma. In Berggsma D (ed): Birth Defects Compendium, 2nd Ed. New York, Alan R. Liss, Inc., 1979, pp $784-785$.

29. Whitaker SR, Sprinkle PM, Chou SM. Nasal glioma. Arch Otolaryngol 107:550-554, 1981.

30. Orkin M, Fisher I. Heterotopic brain tissue (heterotopic neural rest). Arch Dermatol 94:699-708, 1966.

31. Pasyk KA, Argenta LC, Marks MW, Friedman RJ. Heterotopic brain presenting as a lip lesion. Cleft Palate ] 25:48-52, 1988.

32. Alexander TA. Nasal glioma. J Pediatric Surg 13:522-524, 1978.

33. Ruff T, Diaz JA. Heterotopic brain in the nasopharynx. Otolaryngol Head Neck Surg 94:254-256, 1986.

34. Ofodile FA, Aghadiuno PU, Oyemade O, Adebonojo T. Heterotopic brain in the tongue. Plast Reconstr Surg 69:120-124, 1982.

35. Birnbaum LM, Oesley JQ Jr. Frontonasal tumors of neurogenic origin. Plast Reconstr Surg 41:462-470, 1968.

36. Davis $\mathrm{CH} \mathrm{Jr}$, Alexander $\mathrm{E}$ Jr. Congenital nasofrontal encephalomeningoceles and teratomas: Review of seven cases. J Neurosurg 16:365-377, 1959.

37. Bradley PJ, Singh SD. Nasal glioma. J Laryngol Otol 99:247$252,1985$.

38. Hirsh LF, Stool SE, Langfitt TW, Schut L. Nasal glioma. J Neurosurg 46:85-91, 1977.

39. Smith KR Jr, Schwartz HG, Luse SA, Ogura JH. Nasal gliomas: A report of five cases with electron microscopy of one. J Neurosurg 20:968-982, 1963.

40. Patterson K, Kapus S, Chandra RS. Nasal gliomas and related brain neterotopias: A pathologists' perspective. Ped Pathol 5:353-362, 1986

41. Younus $M$, Coode PE. Nasal glioma and encephalocele: Two separate entities. J Neurosurg 64:516-519, 1986.

42. Emery JL, Kalhan SC. The pathology of exencephalus. Dev Med Child Neurol 22:51-64, 1970.

43. Blumenfeld R, Skolnick EM. Intranasal encephaloceles. Arch Otolaryngol 82:527-531, 1965.

44. Shulman K. Meningocele. In Bergsma D (ed): Birth Defects Compendium, 2nd Ed. New York, Alan R. Liss, Inc., 1979, pp 390391.

45. Shah AK, Desai AA, Sharma SN, Udwadia RB. Fronto ethmoidal meningoencephalocystocele. Ann Plast Surg 22:523-527, 1989.

46. Diebler C, Dulac O. Cephaloceles: Clinical and neuroradiological appearance. Neuroradiol 25:199-216, 1983

47. Donnenfeld AE, Hughes $H$, Weiner $S$. Prenatal diagnosis and perinatal management of fronto ethmoidal meningoencephalocele. Am J Perinatol 5:51 -53, 1988.

48. McLaurin RL. Parietal cephaloceles. Neurology 14:764-722, 1964.

49. Cohen MH, Lemire RJ. Syndromes with cephaloceles. Teratology 25:161-172, 1982.

50. New GB, Erich JB. Dermoid cysts of the head and neck. Surg Gynecol Obstet 65:48-55, 1937.

51. Crawford JK, Webster JP. Congenital dermoid cysts of the nose. Plast Reconstr Surg 9:235-260, 1952.

52. Plewes J, Jacobson I. Familial frontonasal dermoid cyst. J Neurosurg 34:683-686, 1971.

53. Baarsma EA. The median nasal sinus and dermoid cyst. Arch Dermatol 226:107-113, 1980.

54. Brownstein MH, Helwig EB. Subcutaneous dermoid cysts. Arch Dermatol 107:237-239, 1973.

55. Mulliken JB. Diagnosis and natural history of hemangiomas. In Mulliken JB, Young AE (eds): Vascular Brithmarks: Hemangiomas and Malformations. Philadelphia, WB Saunders, 1988, pp 41-62. 
56. Ferguson $C F$, Flake CG. Subglottic hemangioma as a cause of respiratory obstruction in infants. Ann Otol Rhinol Laryngol 70:1095-1112, 1961.

57. Johnson GF, Weisman PA. Radiologic features of dermoid cysts of the nose. Radiology 82:1016-1021, 1964.

58. Lusk RP, Lee PC. Magnetic resonance imaging of congenital midline nasal masses. Otolaryngol Head Neck Surg 95:303-306, 1986.

59. Lusk RP, Dunn VD. Magnetic resonance imaging in encephaloceles. Ann Otol Rhinol Laryngol 95:432-433, 1986.
60. Mulliken JB. Treatment of hemangiomas. In Mulliken JB, Young AE (eds): Vascular Birthmarks: Hemangiomas and Malformations. Philadelphia, WB Saunders, 1988, pp 77-103.

61. Nakamura T, Grant JA, Hubbard RE. Nasoethmoidal meningoencephalocele. Arch Otolaryngol 100:62-64, 1974.

62. Lowe RS, Robinson DW, Ketchum LD, Masters FW. Nasal gliomata. Plast Reconstr Surg 47:1-5, 1971.

63. Grundfast KM, Mihail R, Majd M. Intraoperative detection of cerebrospinal fluid leak in surgical removal of congenital nasal masses. Laryngoscope 96:211, 1986. 